\title{
Association between skeletal muscle mass and serum concentrations of lipoprotein lipase, GPIHBP1, and hepatic triglyceride lipase in young Japanese men
}

Ryutaro Matsumoto ${ }^{1}$, Katsuhiko Tsunekawa ${ }^{1 *}$ (D), Yoshifumi Shoho ${ }^{1,2}$, Yoshimaro Yanagawa ${ }^{1,2}$, Nobuo Kotajima ${ }^{1,3}$, Shingo Matsumoto ${ }^{4}$, Osamu Araki ${ }^{1}$, Takao Kimura', Katsuyuki Nakajima and Masami Murakami ${ }^{1}$

\begin{abstract}
Background: Two important regulators for circulating lipid metabolisms are lipoprotein lipase (LPL) and hepatic triglyceride lipase (HTGL). In relation to this, glycosylphosphatidylinositol anchored high-density lipoprotein binding protein 1 (GPIHBP1) has been shown to have a vital role in LPL lipolytic processing. However, the relationships between skeletal muscle mass and lipid metabolism, including LPL, GPIHBP1, and HTGL, remain to be elucidated. Demonstration of these relationships may lead to clarification of the metabolic dysfunctions caused by sarcopenia. In this study, these relationships were investigated in young Japanese men who had no age-related factors; participants included wrestling athletes with abundant skeletal muscle.
\end{abstract}

Methods: A total of 111 young Japanese men who were not taking medications were enrolled; 70 wrestling athletes and 41 control students were included. The participants' body compositions, serum concentrations of lipoprotein, LPL, GPIHBP1 and HTGL and thyroid function test results were determined under conditions of no extreme dietary restrictions and exercises.

Results: Compared with the control participants, wrestling athletes had significantly higher skeletal muscle index (SMI) $(p<0.001)$, higher serum concentrations of LPL $(p<0.001)$ and GPIHBP1 $(p<0.001)$, and lower fat mass index $(p=0.024)$. Kruskal-Wallis tests with Bonferroni multiple comparison tests showed that serum LPL and GPIHBP1 concentrations were significantly higher in the participants with higher SMI. Spearman's correlation analyses showed that SMI was positively correlated with LPL $(\rho=0.341, p<0.001)$ and GPIHBP1 $(\rho=0.309, p=0.001)$ concentration. The serum concentrations of LPL and GPIHBP1 were also inversely correlated with serum concentrations of triglyceride ( $L P L, \rho=-0.198, p=0.037 ;$ GPIHBP1, $\rho=-0.249, p=0.008$ ). Serum HTGL concentration was positively correlated with serum concentrations of total cholesterol $(\rho=0.308, p=0.001)$, low-density lipoprotein-cholesterol $(\rho=0.336, p<0.001)$, and free $3,5,3^{\prime}$-triiodothyronine ( $\left.\rho=0.260, p=0.006\right)$, but not with SMI.

Conclusions: The results suggest that increased skeletal muscle mass leads to improvements in energy metabolism by promoting triglyceride-rich lipoprotein hydrolysis through the increase in circulating LPL and GPIHBP1.

Keywords: Skeletal muscle mass, Lipoprotein lipase (LPL), Glycosylphosphatidylinositol anchored high-density lipoprotein binding protein 1 (GPIHBP1), Hepatic triglyceride lipase (HTGL), Thyroid hormone

\footnotetext{
* Correspondence: ktsune@gunma-u.ac.jp

'Department of Clinical Laboratory Medicine, Gunma University Graduate

School of Medicine, Maebashi 371-8511, Japan

Full list of author information is available at the end of the article
}

(c) The Author(s). 2019 Open Access This article is distributed under the terms of the Creative Commons Attribution 4.0 International License (http://creativecommons.org/licenses/by/4.0/), which permits unrestricted use, distribution, and reproduction in any medium, provided you give appropriate credit to the original author(s) and the source, provide a link to the Creative Commons license, and indicate if changes were made. The Creative Commons Public Domain Dedication waiver (http://creativecommons.org/publicdomain/zero/1.0/) applies to the data made available in this article, unless otherwise stated. 


\section{Background}

The skeletal muscle is a major organ involved in systemic energy metabolism. As the population is aging rapidly, the increase in the number of patients with decreased skeletal muscle mass, called sarcopenia, is becoming an evident clinical problem. It is known that sarcopenia is associated with cardiovascular diseases and metabolic disorders, including dyslipidemia [1-5]; however, the detailed mechanism of metabolic dysfunction by sarcopenia remains to be clarified. It is believed that one way to prevent metabolic diseases is to maintain an appropriate amount of skeletal muscle through physical activities, such as exercise. However, there have been few reports on the effects of increasing skeletal muscle mass on lipid metabolism.

Two key enzymes involved in circulating lipid metabolism are lipoprotein lipase (LPL) and hepatic triglyceride lipase (HTGL) [6-9]. LPL has a major role in triglyceride (TG)-rich lipoprotein metabolism by catalyzing the hydrolysis of TG in chylomicrons and very low-density lipoproteins to form chylomicron and very low-density lipoprotein remnants, respectively [6, 7]. LPL is expressed and synthesized mainly in adipose and skeletal muscle tissue that store and consume fatty acids, respectively, and is translocated to the capillary lumen by glycosylphosphatidylinositol anchored high-density lipoprotein (HDL) binding protein 1 (GPIHBP1) [8]. GPIHBP1 anchors the LPL on the surface of capillary endothelial cells and has a crucial role in the lipolytic processing of TG-rich lipoproteins by LPL [7, 8]. Recent reports have demonstrated that GPIHBP1 autoantibodies and gene mutations cause hypertriglyceridemia [10-16]. Regarding HTGL, it has been known that it has a role in catalyzing the hydrolysis of the smaller remnants into low-density lipoprotein (LDL) and has a primary role in HDL metabolism [9, 17]. HTGL is synthesized in the liver and bound to heparin sulfate proteoglycans on surfaces of the liver sinusoidal capillaries $[9,17]$.

Thyroid hormone has a crucial role in lipid metabolism [18]. Higher levels of serum remnant-like particle cholesterol (RLP-C), which is the atherogenic lipoprotein, have been found in patients with hypothyroidism and subclinical hypothyroidism compared with matched controls, and their RLP-C concentrations were decreased after levothyroxine therapy $[19,20]$. There have been reports that levothyroxine therapy increases plasma LPL [19] and HTGL [19, 20] activities. However, the correlations between serum free thyroid hormone concentrations and LPL, HTGL, and GPIHBP1 concentrations have not been fully elucidated.

Extensive studies on the tissue-specific activities of lipases in animal models and circulating activities and concentrations of lipases in plasma have been conducted to clarify the biological functions of LPL and HTGL $[6,7]$.
Studies were conducted to specially investigate LPL's association with exercise because of expression in skeletal muscle. Previous reports have proven that regular exercise lowers serum TG concentrations through increases in muscle and serum LPL activities [7, 21]. In contrast, it has been shown that decreased serum LPL concentrations are associated with metabolic syndrome, diabetes, and coronary atherosclerosis [22-26]. In the case of HTGL, although its pathophysiologic role has been investigated mainly in terms of association with atherosclerosis, by measurement of circulating HTGL activities, studies have indicated contradictory results regarding associations with atherosclerosis [27-31]. In the past, owing to the low sensitivities of assays, previous methods used for measuring circulating activities and concentrations of lipases required heparin administration. Therefore, assay methods based on the monoclonal antibodies against these lipases have been developed recently to achieve sufficient sensitivities for measurement of serum LPL and HTGL concentrations without the need for heparin administration [32-34]. As a result, preheparin serum LPL concentrations can now be measured using a latex particle-enhanced turbidimetric immunoassay with an automated analyzer [35], and preheparin serum HTGL concentrations can be determined using high-sensitivity HTGL enzyme-linked immunosorbent assay (ELISA) [34]. Furthermore, ELISA methods have been developed recently for the measurement of serum concentrations of GPIHBP1 [36].

These methods were used in two recent studies to demonstrate the clinical relevance of preheparin serum concentrations of LPL and HTGL and serum concentrations of GPIHBP1. The first study reported that in patients with coronary artery disease, increases in atherogenic lipoproteins, such as RLP-C, were associated with an increase in preheparin serum HTGL concentration and a decrease in preheparin serum LPL concentration [37]. The second study demonstrated that in obese middle-aged women, a diet and exercise intervention contributed to increased serum GPIHBP1 concentration, but not LPL concentrations, in association with a decrease in body weight and body fat [38]. However, these two studies found that multiple factors influenced lipid metabolism because most participants were older people who had arteriosclerosis or metabolic disorders and took medication, including statins. Furthermore, the relationship between skeletal muscle mass and lipid metabolism, including LPL, GPIHBP1, and HTGL, remains to be elucidated. One effective way to clarify these relationships is to conduct an investigation on young individuals with abundant skeletal muscle who do not have age-related factors. In addition, presentation of these relationships may lead to a clarification of the mechanisms involved in metabolic dysfunctions caused by sarcopenia. 
In this study, the aims were to analyze the characteristics of body composition and serum lipid metabolism and investigate the association between skeletal muscle mass and serum concentrations of LPL, GPIHBP1, and HTGL in young Japanese men, which included skeletal muscle-rich wrestling athletes, who did not have metabolic disorders or arteriosclerosis.

\section{Materials and methods}

\section{Participants}

Participants in this cross-sectional study included 111 young, healthy Japanese men who were not taking medications for metabolic diseases. Seventy were amateur wrestlers (age range, 16-26 years) and 41 were college students who did not engage in habitual hard exercise (age range, 18-24 years). In general, wrestling athletes begin to decrease their food intake for weight loss and to exercise hard at approximately 2 weeks before a wrestling tournament with weight categories [39]. In this study, wrestling athletes' body compositions, serum lipoproteins, lipases, and lipase-associated protein were determined during periods wherein they were not under dietary restrictions or were not undergoing hard practices for a tournament.

Participants provided written informed consent before being included in the study. The ethics committee of Gunma University Graduate School of Medicine approved this study (approval no. 13-36).

\section{Physical examinations}

Physical examinations and blood sample collections were performed in the morning after a 12 -h fast. A bioimpedance instrument (InBody 430; InBody Japan, Tokyo, Japan) was used to measure body weight, fat mass, and skeletal muscle mass, with the participant in the standing position. Body mass index (BMI), fat mass index (FMI), and skeletal muscle index (SMI) were calculated respectively as follows: weight/height squared $\left(\mathrm{kg} / \mathrm{m}^{2}\right)$, fat mass/height squared $\left(\mathrm{kg} / \mathrm{m}^{2}\right)$, and skeletal muscle mass/height squared $\left(\mathrm{kg} / \mathrm{m}^{2}\right)$.

\section{Measurement of thyroid function and serum concentrations of lipoprotein, lipases, and lipase- associated protein}

With the participants sitting down, blood samples were collected after an antecubital vein is punctured using 23-G needles. Serum samples were separated by centrifugation $(1500 \times g)$ at $4{ }^{\circ} \mathrm{C}$ for $10 \mathrm{~min}$ and were stored at $-80^{\circ} \mathrm{C}$ until analysis. A chemiluminescent microparticle immunoassay on an Abbott ARCHITECT i2000SR Immunoassay Analyzer (Abbott Laboratories, Abbott Park, Illinois) was used to analyze the serum concentrations of free 3,5,3'-triiodothyronine $\left(\mathrm{FT}_{3}\right)$, free thyroxine $\left(\mathrm{FT}_{4}\right)$, and thyrotropin (TSH). Enzymatic methods using a
LABOSPECT 008 automatic analyzer (Hitachi, Tokyo, Japan) were carried out to measure serum total cholesterol (TC), HDL cholesterol (HDL-C), and TG concentrations. The Friedewald formula was used to determine LDL cholesterol (LDL-C) concentrations: LDL-C $=\mathrm{TC}-$ HDL-C - TG/5 [40].

LPL latex agglutination turbidimetry (Immuno-Biological Laboratories [IBL], Gunma, Japan) was used to measure serum LPL concentrations [35]. A Human GPIHBP1 Assay Kit (IBL) based on sandwich ELISA was used to determine serum GPIHBP1 concentrations [36]. Finally, the Human Serum HTGL ELISA Kit (IBL) was used to measure serum HTGL concentrations [34].

\section{Statistical analysis}

Because almost all variables were not normally distributed, data are expressed as median values with a 25 th -75 th percentile range, rather than as mean values with standard deviations. Unpaired Student's $t$ tests or Mann-Whitney $U$ tests were used, as appropriate, to identify statistically significant differences between the two study groups. Kruskal-Wallis tests with Bonferroni multiple comparison tests were performed to compare the two groups classified by quartile. Spearman's correlation analyses were carried out to determine the relationships between serum concentrations of LPL, GPIHBP1, or HTGL and the clinical parameters. Differences and correlations were considered significant when $p<0.05$. SPSS Statistics version 25.0 (SPSS, Inc., Chicago, Illinois) was used to perform all statistical analyses.

\section{Results}

\section{Clinical characteristics in control and wrestling athlete} participants

The 111 young Japanese men were divided into two groups: control participants $(n=41)$, who did not engage in habitual hard exercise, and wrestling athletes $(n=70)$. Table 1 shows the results of the physical examinations and lipid metabolism analyses in the two groups. Compared with participants in the control group, participants in the athlete group had significantly higher weights $(p=0.012)$, BMI $(p<0.001)$, and SMI $(p<0.001)$ and lower FMI $(p=0.024)$. Similarly, lipid metabolism analyses showed that the athlete group participants had significantly higher serum concentrations of HDL-C ( $p$ $=0.016)$, LPL $(p<0.001)$, and GPIHBP1 $(p<0.001)$. Serum concentrations of TG tended to be lower in athletes, although the differences between the two groups were not statistically significant $(p=0.288)$. There were no differences in serum HTGL concentrations and thyroid function tests between the groups. Results of the thyroid function tests showed values that were within reference range in all participants. 
Table 1 Clinical Characteristics in Control and Wrestling Athlete Participants

\begin{tabular}{|c|c|c|c|c|}
\hline & $\begin{array}{l}\text { All Participants } \\
(n=111)\end{array}$ & $\begin{array}{l}\text { Control Participants } \\
(n=41)\end{array}$ & $\begin{array}{l}\text { Athletes } \\
(n=70)\end{array}$ & $p$ \\
\hline Age (years) & $20(19.0-21.0)$ & $19(18.0-20.0)$ & $20(19.0-21.0)$ & 0.001 \\
\hline Weight (kg) & $66.6(62.3-74.2)$ & $64.2(58.1-68.4)$ & $68.4(63.6-75.9)$ & 0.012 \\
\hline $\mathrm{BMI}\left(\mathrm{kg} / \mathrm{m}^{2}\right)$ & $23.7(22.2-25.6)$ & $21.7(20.1-24.0)$ & $24.2(23.2-26.0)$ & $<0.001$ \\
\hline $\mathrm{FMI}\left(\mathrm{kg} / \mathrm{m}^{2}\right)$ & $2.7(2.3-3.7)$ & $3.2(2.3-4.9)$ & $2.6(2.2-3.5)$ & 0.024 \\
\hline $\mathrm{SMI}\left(\mathrm{kg} / \mathrm{m}^{2}\right)$ & $11.9(11.0-12.5)$ & $10.5(9.9-11.5)$ & $12.4(11.9-13.0)$ & $<0.001$ \\
\hline $\mathrm{TC}(\mathrm{mg} / \mathrm{dL})$ & $168(150-186)$ & $171(156-186)$ & $167(145-186)$ & 0.452 \\
\hline $\mathrm{LDL}-\mathrm{C}(\mathrm{mg} / \mathrm{dL})$ & $94(83-110)$ & $100(85-115)$ & $93(82-105)$ & 0.282 \\
\hline $\mathrm{HDL}-\mathrm{C}(\mathrm{mg} / \mathrm{dL})$ & $56(51-66)$ & $53(48-63)$ & $59(53-67)$ & 0.016 \\
\hline $\mathrm{TG}(\mathrm{mg} / \mathrm{dL})$ & $64(49-81)$ & $66(49-101)$ & 64 (49-76) & 0.288 \\
\hline LPL (ng/mL) & $62.5(52.5-72.6)$ & $52.3(47.6-59.0)$ & $67.3(60.2-76.0)$ & $<0.001$ \\
\hline GPIHBP1 $(p g / m L)$ & $986(853-1150)$ & 934 (742-1039) & 1038 (890-1283) & $<0.001$ \\
\hline HTGL (ng/mL) & $44.1(33.1-61.1)$ & $43.9(34.6-61.3)$ & $45.5(30.0-61.0)$ & 0.525 \\
\hline $\mathrm{FT}_{3}(\mathrm{pg} / \mathrm{mL})$ & $3.22(3.09-3.39)$ & $3.18(3.04-3.34)$ & $3.23(3.10-3.41)$ & 0.115 \\
\hline $\mathrm{FT}_{4}(\mathrm{ng} / \mathrm{dL})$ & $1.04(0.98-1.10)$ & $1.02(0.98-1.10)$ & $1.05(0.97-1.11)$ & 0.318 \\
\hline $\mathrm{TSH}(\mu \mathrm{lU} / \mathrm{mL})$ & $1.78(1.24-2.25)$ & $1.84(1.19-2.12)$ & $1.67(1.36-2.30)$ & 0.647 \\
\hline
\end{tabular}

Data are expressed as median (25th-75th percentile)

Wrestling athletes were compared with control participants using the unpaired Student's $t$ test or Mann-Whitney $U$ test as appropriate

$B M I$ body mass index, FMI fat mass index, SMI skeletal muscle index, $T C$ total cholesterol, $L D L-C$ low-density lipoprotein cholesterol, $H D L-C$ high-density lipoprotein cholesterol, TG triglyceride, LPL lipoprotein lipase, GPIHBP1 glycosylphosphatidylinositol anchored high-density lipoprotein binding protein 1, HTGL hepatic

triglyceride lipase, $F T_{3}$ free 3,5,3'-triiodothyronine, $F T_{4}$ free thyroxine, $T S H$ thyrotropin

\section{Association between SMI and serum concentrations of LPL, GPIHBP1, and HTGL}

Figure 1 shows the associations between SMI and serum concentrations of LPL, GPIHBP1, and HTGL in all participants. Figure 1a shows the comparison of serum concentrations of LPL, GPIHBP1, and HTGL between the SMI groups classified by quartile. The SMI values of each group are as follows: group $1, \mathrm{SMI} \leq 11.0$; group 2, $11.0<\mathrm{SMI} \leq 11.9$; group $3,11.9<\mathrm{SMI} \leq 12.5$; and group $4,12.5<$ SMI. Kruskal-Wallis tests indicate that there were significant differences among the SMI groups in serum concentrations of LPL $(p<0.001)$ and GPIHBP1 $(p=0.011)$. Moreover, Bonferroni multiple comparison tests show that the serum concentrations of LPL in groups 3 and 4 were significantly higher than that in group 1, and serum concentrations of GPIHBP1 in group 4 were significantly higher than that in group 1 . There was no significant difference in serum HTGL concentrations among the SMI groups. In addition, results of the Spearman's correlation analyses show that SMI was positively correlated with LPL $(\rho=0.341, p<0.001)$ and GPIHBP1 $(\rho=0.309, p=0.001)$ concentration but was not correlated with HTGL concentration ( $\rho=-$ 0.013, $p=0.891$ ) (Fig. 1b). Weight-adjusted skeletal muscle mass, calculated as skeletal muscle mass/weight, was also correlated with LPL $(\rho=0.364, p<0.001)$ and GPIHBP1 $(\rho=0.206, p=0.022)$ concentration (data not shown).

\section{Correlation between LPL and GPIHBP1 concentrations and clinical variables}

Figure 2a shows the results of the Spearman's correlation analyses between GPIHBP1 and LPL or HTGL concentrations in all participants. Results indicate that LPL concentration was positively correlated with GPIHBP1 concentration $(\rho=0.251, p=0.008)$. In contrast, HTGL concentration was not correlated with GPIHBP1 concentrations $(\rho=0.057, p=0.553)$. Table 2 shows the correlation between serum concentrations of LPL and GPIHBP1 and other clinical variables in all participants. LPL concentration were positively correlated with SMI and HDL-C $(\rho=0.389, p<0.001)$ and inversely correlated with FMI $(\rho=-0.222, p=0.019)$ and TG $(\rho=-0.198, p=$ 0.037; Fig. 2b). Moreover, GPIHBP1 concentrations were positively correlated with SMI and inversely correlated with TG $(p=-0.249, p=0.008 ;$ Fig. $2 b)$. LPL and GPIHBP1 concentrations were not correlated with results of the thyroid function tests.

\section{Correlation between HTGL concentrations and clinical variables}

Table 2 and Fig. 3 show the results of the Spearman's correlation analyses between HTGL concentrations and other clinical variables in all participants. HTGL concentration was positively correlated with TC $(\rho=0.308, p=$ $0.001)$, LPL-C $(\rho=0.336, p<0.001)$, and $\mathrm{FT}_{3}(\rho=0.260$, $p=0.006)$ concentrations but was not correlated with 


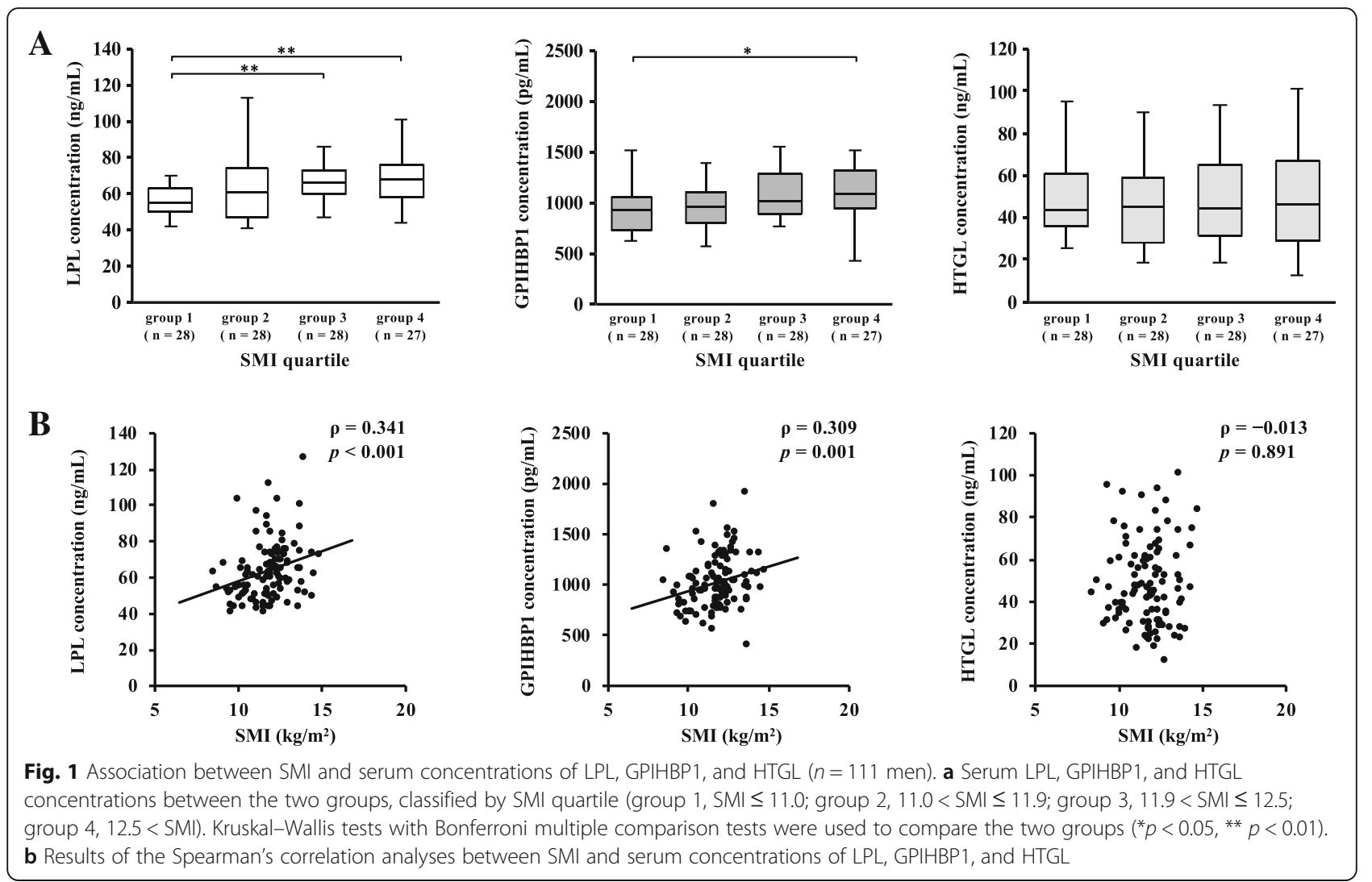

$\mathrm{FT}_{4}$ and $\mathrm{TSH}$ concentrations. $\mathrm{FT}_{3}, \mathrm{FT}_{4}$, and TSH concentrations were not correlated with any data from the physical examination or lipoprotein analyses (data not shown).

\section{Discussion}

The analyses in this study show the associations between skeletal muscle mass and lipid metabolism, including LPL, GPIHBP1, and HTGL, in young Japanese men. Significantly high serum concentrations of preheparin LPL and GPIHBP1 were found in wrestling athletes with abundant skeletal muscle mass. Participants with higher SMI showed significantly higher serum concentrations of LPL and GPIHBP1. Moreover, in all participants, serum concentrations of LPL and GPIHBP1 correlated positively with SMI and inversely with TG concentrations. Serum HTGL concentration was positively correlated with $\mathrm{TC}$, LDL-C, and $\mathrm{FT}_{3}$ concentrations but not was correlated with skeletal muscle mass.

Previous studies have shown that preheparin serum LPL concentrations were positively correlated with HDL-C concentration and inversely correlated with TG concentration [22, 37, 41-43]. In addition, it has been reported that LPL concentration is inversely correlated with intra-abdominal visceral fat accumulation, as evaluated by computed tomography [22], and with the number of metabolic syndrome symptoms [23]. In agreement with these studies, we observed correlations of LPL with lipoprotein concentrations and FMI. Some studies have identified several GPIHBP1 gene missense mutations that cause chylomicronemia $[8,10-15]$. These mutations block the ability of GPIHBP1 to bind LPL and shuttle it to the capillary lumen owing to the disruption to fold the lymphocyte antigen 6/urokinase-type plasminogen activator receptor domain that binds LPL with high affinity [10-15]. In addition, recent reports have identified the presence of GPIHBP1 antibodies that inhibit the ability of GPIHBP1 to bind and transport LPL in patients with hypertriglyceridemia [16]. The positive correlation between GPIHBP1 and TG concentrations in this study agrees with the relevance reported in these previous studies. In addition, in agreement with a previous study [37], there was a positive correlation between GPIHBP1 concentration and LPL concentration, but there was no correlation between GPIHBP1 concentration and HTGL concentration. On one hand, several studies on humans have revealed that physical exercise leads to an increase in LPL activity and mRNA in the exercising muscle [44-48] and to an increase in postheparin plasma LPL activity and preheparin serum LPL concentration $[49,50]$. On the other hand, one study [38] reported an association between GPIHBP1 concentration and physical exercise, wherein reduction in 

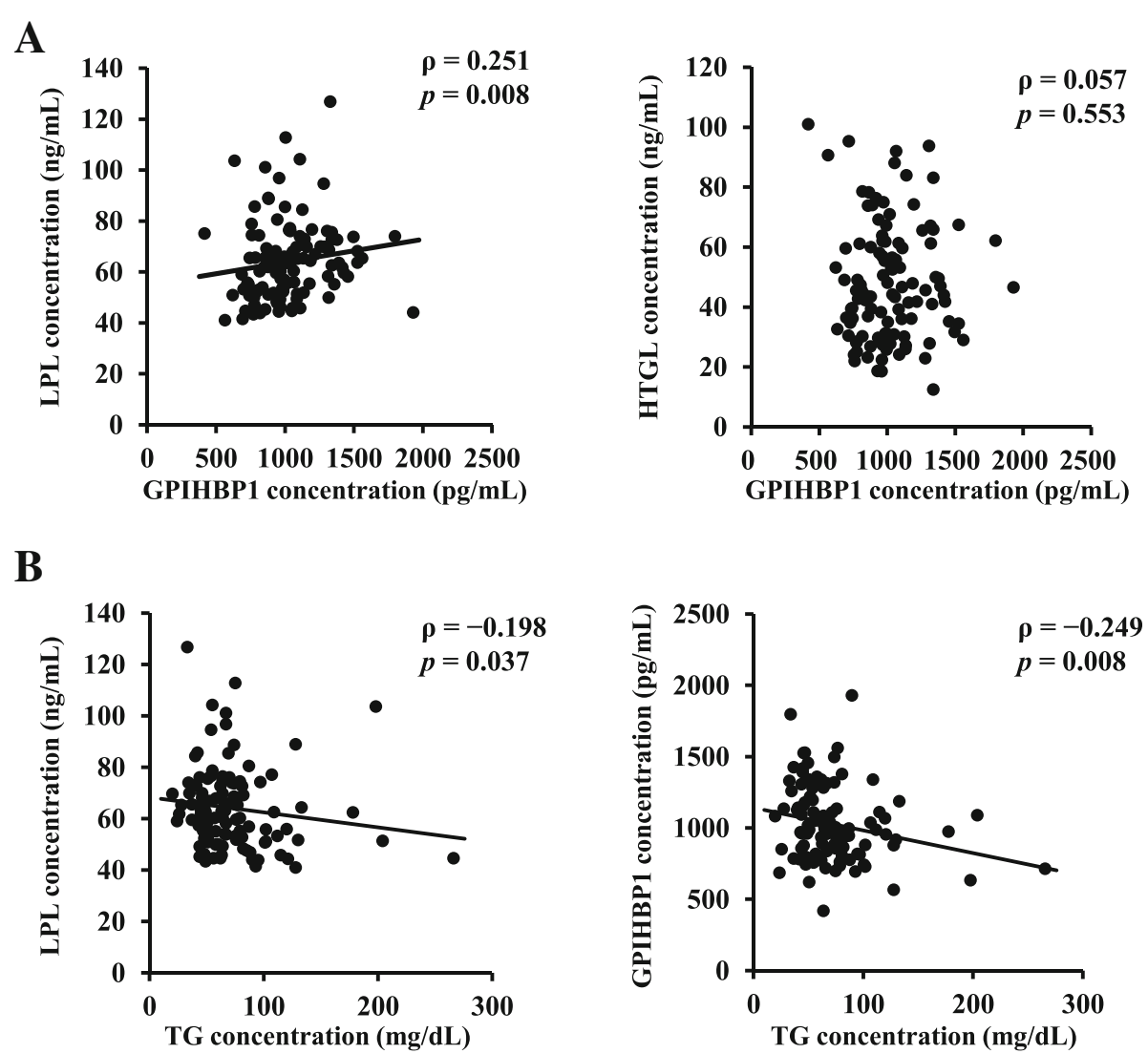

Fig. 2 Correlations between serum LPL and GPIHBP1 concentrations and clinical variables ( $n=111$ men). Results of the Spearman's correlation analyses (a) between serum GPIHBP1 concentrations and serum LPL and HTGL concentrations and (b) between serum TG concentration and serum LPL and GPIHBP1 concentrations

Table 2 Spearman's correlation analyses between LPL, GPIHBP1, and HTGL concentrations and clinical variables in 111 participants

\begin{tabular}{|c|c|c|c|c|c|c|}
\hline \multirow[b]{2}{*}{ Variable $(n=111)$} & \multicolumn{2}{|l|}{$L P L$} & \multicolumn{2}{|c|}{ GPIHBP1 } & \multicolumn{2}{|l|}{ HTGL } \\
\hline & $\rho$ & $p$ & $\rho$ & $p$ & $\rho$ & $\rho$ \\
\hline Age (years) & 0.053 & 0.577 & -0.059 & 0.542 & 0.065 & 0.501 \\
\hline Neight (kg) & 0.075 & 0.432 & 0.153 & 0.109 & 0.065 & 0.496 \\
\hline BMI $\left(\mathrm{kg} / \mathrm{m}^{2}\right)$ & 0.123 & 0.199 & 0.167 & 0.081 & 0.087 & 0.361 \\
\hline FMI $\left(\mathrm{kg} / \mathrm{m}^{2}\right)$ & -0.222 & 0.019 & -0.143 & 0.135 & 0.112 & 0.210 \\
\hline $\mathrm{Ml}\left(\mathrm{kg} / \mathrm{m}^{2}\right)$ & 0.341 & $<0.001$ & 0.309 & 0.001 & -0.013 & 0.891 \\
\hline $\mathrm{TC}(\mathrm{mg} / \mathrm{dL})$ & -0.003 & 0.976 & -0.167 & 0.080 & 0.308 & 0.001 \\
\hline DL-C (mg/dL) & -0.079 & 0.413 & -0.064 & 0.504 & 0.336 & $<0.001$ \\
\hline $\mathrm{HDL}-\mathrm{C}(\mathrm{mg} / \mathrm{dL})$ & 0.389 & $<0.001$ & 0.003 & 0.974 & -0.092 & 0.337 \\
\hline TG (mg/dL) & -0.198 & 0.037 & -0.249 & 0.008 & 0.057 & 0.551 \\
\hline$T_{3}(p g / m L)$ & 0.161 & 0.092 & 0.017 & 0.862 & 0.260 & 0.006 \\
\hline $\mathrm{FT}_{4}(\mathrm{ng} / \mathrm{dL})$ & 0.139 & 0.146 & 0.086 & 0.371 & 0.035 & 0.712 \\
\hline TSH ( $\mu \mathrm{IU} / \mathrm{mL})$ & 0.121 & 0.204 & 0.003 & 0.971 & -0.041 & 0.669 \\
\hline
\end{tabular}

weight as a result of a diet and exercise intervention increased serum GPIHBP1 concentration, but not serum LPL concentration, in Japanese women who were obese. However, the relationship between LPL and GPIHBP1 and skeletal muscle mass, including sarcopenia, has not been fully understood. In this study, there were significantly higher LPL and GPIHBP1 concentrations in wrestling athletes than in control participants. This difference may be affected not only by the quantity but also the quality of athletes' muscle with continuing habitual trainings, but the multiple comparison analysis and the correlation analysis among all participants, including controls, also indicated that the participants with higher SMI had higher LPL and GPIHBP1 concentrations as well. To our knowledge, this is the first study to report on the relevance of the relationship between skeletal muscle mass and serum concentration of GPIHBP1, as well as serum concentrations of LPL. The results of this study suggest that increased skeletal muscle mass results in effective energy use through the promotion of TG-rich lipoprotein hydrolysis through elevation of serum LPL and GPIHBP1 concentrations. Conversely, unlike LPL, GPIHBP1 concentration was not correlated 

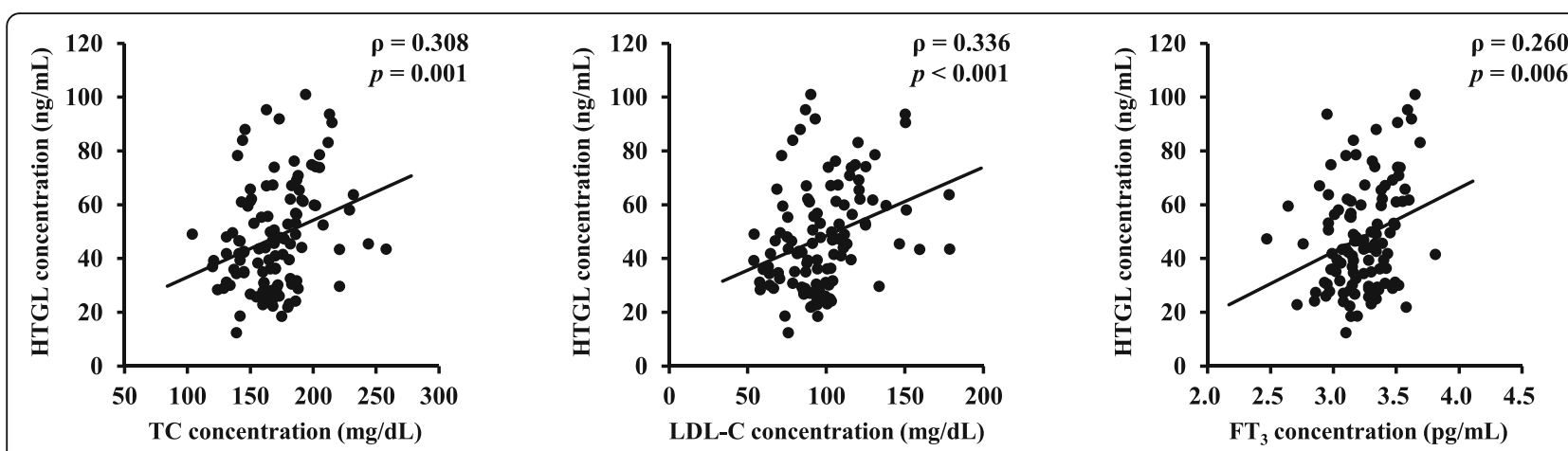

Fig. 3 Correlations between serum HTGL concentrations and clinical variables ( $n=111$ men). Results of the Spearman's correlation analyses between serum HTGL concentration and TC, LDL-C, and FT 3 concentration

with FMI and HDL-C concentrations. Future studies are needed to explore these distinctions in correlations through clinical and molecular analyses and to investigate the association between these proteins and the qualities of skeletal muscle, such as slow-stich muscle and fast-stich muscle.

The inverse relation between HTGL activities and the buoyancies and sizes of LDL and HDL particles has been shown in one study [9]. In addition, in the last decade, a number of studies have reported on increases and decreases in HTGL activities associated with atherosclerosis [27-31]. In a recent study [37] using high-sensitivity ELISA for patients with coronary artery diseases, preheparin serum HTGL concentrations were positively correlated with small dense LDL-C (sdLDL-C) and RLP-C concentrations, but not with LDL-C or large-buoyant LDL-C concentrations. However, because most participants in that study were taking statins, only the positive correlations with sdLDL-C, which is unlikely to be affected by statins, were considered. In contrast, in the young participants in this study, age, medication use, or anamnestic factors had no effect on lipid metabolism, which were likely reflected by the positive correlation between HTGL and LDL-C concentrations. Moreover, in this study, there were no differences in serum HTGL concentrations between the athletes and the control participants, and there was no correlation between the HTGL concentration and skeletal muscle mass. This suggests that HTGL is produced by hepatocytes, but not by skeletal muscle cells $[9,17]$.

Previous studies have demonstrated that in patients with hypothyroidism who were treated with levothyroxine, increased HTGL activities were associated with decreases in serum RLP-C concentration [19, 20]. Moreover, one study [51] showed that $\mathrm{T}_{3}$ increased the posttranslational HTGL expression in HepG2 cells. However, no direct correlations between HTGL activities and thyroid hormone concentrations were demonstrated. In this study, there was a significant, positive correlation between $\mathrm{FT}_{3}$ and preheparin serum HTGL concentrations in young men with euthyroid state. This correlation provides support for the relationships between HTGL activities and thyroid hormones shown in previous molecular and clinical studies. In this study, however, there were no correlations between serum HTGL concentrations and $\mathrm{FT}_{4}$ and TSH concentrations. The differences in the correlations with HTGL concentration may be attributable to more potent physiologic activity of $\mathrm{T}_{3}$ than that of $\mathrm{T}_{4}$. Our results suggest that HTGL seems to accelerate the synthesis of LDL-C in proportion to serum $\mathrm{FT}_{3}$ concentration. Future studies are needed to determine the detailed effect of thyroid hormone on lipid metabolism, including HTGL, in various thyroid states.

Limitations of this study should be acknowledged, which include the cross-sectional design of the study and the relatively small sample size. One reason for the small sample size is that only men were enrolled in this study. Women were not included because they have menstrual cycles and different body compositions that may have an effect on lipid metabolism. Although there were no participants with sarcopenia in this study who had skeletal muscle mass less than $20 \mathrm{~kg}$ and SMI less than $7.0 \mathrm{~kg} / \mathrm{m}^{2}$, which are cutoff points provided by the European Working Group on Sarcopenia in Older People 2 [52], we focused enrollment on many young wrestling athletes with a large amount of skeletal muscle in the same condition without extreme dietary restrictions and hard practices. Moreover, the control participants were significantly younger than the wrestling athletes, but this may not have been a serious confounder as there was an almost unremarkable difference between the ages of the two groups, and no participant had age-related factors, such as medication use or metabolic diseases. These assertions can also be supported by analyses conducted for other lipid markers, such as RLP-C and sdLDL-C. Moreover, further studies are needed to confirm our hypothesis by evaluating more markers of total energy metabolism in a larger cohort 
that includes women, elderly people, individuals with sarcopenia, and the like.

\section{Conclusions}

In conclusion, the serum concentrations of LPL and GPIHBP1 were significantly high in skeletal muscle-rich participants and were positively correlated with skeletal muscle mass in young Japanese men. These results suggest that increases in skeletal muscle mass lead to improvements in energy use by promoting TG-rich lipoprotein hydrolysis through increases in circulating LPL and GPIHBP1 concentrations. In contrast, high serum concentration of HTGL seems to increase the synthesis of serum LDL-C in proportion to $\mathrm{FT}_{3}$ concentration, regardless of skeletal muscle mass.

\section{Abbreviations}

BMI: Body mass index; ELISA: Enzyme-linked immunosorbent assay; FMI: Fat mass index; $\mathrm{FT}_{3}$ : Free 3,5,3'-triiodothyronine; $\mathrm{FT}_{4}$ : Free thyroxine; GPIHBP1: Glycosylphosphatidylinositol anchored high-density lipoprotein binding protein 1; HDL-C: High-density lipoprotein cholesterol; HTGL: Hepatic triglyceride lipase; LDL-C: Low-density lipoprotein-cholesterol; LPL: Lipoprotein lipase; RLP-C: Remnant-like particles-cholesterol; sdLDLC: Small dense low-density lipoprotein-cholesterol; SMI: Skeletal muscle index; TC: Total cholesterol; TG: Triglyceride; TSH: Thyrotropin

\section{Acknowledgments}

We thank Kazumi Ushiki, Kenichi Yumoto, Mayumi Nishiyama, Tetsuo Machida, Yuji Muraba, Makoto Nara, Akihiro Yoshida, and Tomoyuki Aoki for their technical assistance and helpful discussion.

\section{Funding}

This work was supported by the Ministry of Education, Culture, Sports, Science, and Technology, Japan (grant numbers 18 K07406 [K. Tsunekawa], 17 K08874 [T. Kimura], and 17H04109 [M. Murakami]).

\section{Availability of data and materials}

Please contact the corresponding author for reasonable data requests.

\section{Authors' contributions}

MR participated in the collection and analysis of data and writing of the manuscript. KT, YS, YY, NK, SM, OA, TK, and KN participated in data collection and analysis. MM participated in conception of the study, supervision, and manuscript editing. All authors read and approved the final manuscript.

\section{Ethics approval and consent to participate}

Written informed consent was obtained from all participants. This study was approved by the ethics committee of Gunma University Graduate School of Medicine (Approval number 13-36).

\section{Consent for publication}

Not applicable.

\section{Competing interests}

The authors declare that they have no competing interests.

\section{Publisher's Note}

Springer Nature remains neutral with regard to jurisdictional claims in published maps and institutional affiliations.

\section{Author details}

'Department of Clinical Laboratory Medicine, Gunma University Graduate School of Medicine, Maebashi 371-8511, Japan. ${ }^{2}$ Faculty of Education, Ikuei University, Takasaki 370-0011, Japan. ${ }^{3}$ School of Medical Technology, Faculty of Health Science, Gunma Paz University, Takasaki 370-0006, Japan. ${ }^{4}$ Graduate
School of Health and Sport Science, Nippon Sport Science University, Yokohama 227-0033, Japan.

Received: 8 February 2019 Accepted: 8 March 2019

Published online: 04 April 2019

\section{References}

1. Karakelides $\mathrm{H}$, Nair KS. Sarcopenia of aging and its metabolic impact. Curr Top Dev Biol. 2005:68:123-48.

2. Kim TN, Choi KM. The implications of sarcopenia and sarcopenic obesity on cardiometabolic disease. J Cell Biochem. 2015;116:1171-8.

3. Baek SJ, Nam GE, Han KD, Choi SW, Jung SW, Bok AR, et al. Sarcopenia and sarcopenic obesity and their association with dyslipidemia in Korean elderly men: the 2008-2010 Korea National Health and nutrition examination survey. J Endocrinol Investig. 2014;37:247-60.

4. Ishii S, Tanaka T, Akishita M, Ouchi Y, Tuji T, lijima K, et al. Metabolic syndrome, sarcopenia and role of sex and age: cross-sectional analysis of Kashiwa cohort study. PLoS One. 2014;9:e112718.

5. Sanada K, lemitsu M, Murakami H, Gando Y, Kawano H, Kawakami R, et al. Adverse effects of coexistence of sarcopenia and metabolic syndrome in Japanese women. Eur J Clin Nutr. 2012;66:1093-8.

6. Nilssonehle P, Garfinkel AS, Schotz MC. Lipolytic enzymes and plasma lipoprotein metabolism. Annu Rev Biochem. 1980;49:667-93.

7. Kersten S. Physiological regulation of lipoprotein lipase. Biochim Biophys Acta. 2014;1841:919-33.

8. Fong LG, Young SG, Beigneux AP, Bensadoun $A$, Oberer $M$, Jiang $H$, et al. GPIHBP1 and plasma triglyceride metabolism. Trends Endocrinol Metab. 2016;27:455-69.

9. Brunzell JD, Zambon A, Deeb SS. The effect of hepatic lipase on coronary artery disease in humans is influenced by the underlying lipoprotein phenotype. Biochim Biophys Acta. 2012;1821:365-72.

10. Franssen R, Young SG, Peelman F, Hertecant J, Sierts JA, Schimmel AWM, et al. Chylomicronemia with low postheparin lipoprotein lipase levels in the setting of GPIHBP1 defects. Circ Cardiovasc Genet. 2010;3:169-78.

11. Olivecrona G, Ehrenborg E, Semb H, Makoveichuk E, Lindberg A, Hayden MR, et al. Mutation of conserved cysteines in the Ly 6 domain of GPIHBP1 in familial chylomicronemia. J Lipid Res. 2010;51:1535-45.

12. Charriere S, Peretti N, Bernard S, Di Filippo M, Sassolas A, Merlin M, et al. GPIHBP1 C89F Neomutation and hydrophobic C-terminal domain G175R mutation in two pedigrees with severe hyperchylomicronemia. J Clin Endocrinol Metab. 2011;96:E1675-9.

13. Coca-Prieto I, Kroupa O, Gonzalez-Santos P, Magne J, Olivecrona G,

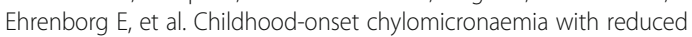
plasma lipoprotein lipase activity and mass: identification of a novel GPIHBP1 mutation. J Intern Med. 2011;270:224-8.

14. Rios JJ, Shastry S, Jasso J, Hauser N, Garg A, Bensadoun A, et al. Deletion of GPIHBP1 causing severe chylomicronemia. J Inherit Metab Dis. 2012;35:531-40.

15. Beigneux AP, Fong LG, Bensadoun A, Davies BSJ, Oberer M, Gardsvoll H, et al. GPIHBP1 missense mutations often cause Multimerization of GPIHBP1 and thereby prevent lipoprotein lipase binding. Circ Res. 2015;116:624-32.

16. Beigneux AP, Miyashita K, Ploug M, Blom DJ, Ai M, Linton MRF, et al. Autoantibodies against GPIHBP1 as a cause of hypertriglyceridemia. N Engl J Med. 2017:376:1647-58.

17. Perret B, Mabile L, Martinez L, Terce F, Barbaras R, Collet X. Hepatic lipase: structure/function relationship, synthesis, and regulation. J Lipid Res. 2002; 43:1163-9.

18. Duntas LH. Thyroid disease and lipids. Thyroid. 2002;12:287-93.

19. Ito M, Takamatsu J, Matsuo T, Kameoka K, Kubota S, Fukata S, et al. Serum concentrations of remnant-like particles in hypothyroid patients before and after thyroxine replacement. Clin Endocrinol. 2003;58:621-6.

20. Brenta G, Berg G, Miksztowicz V, Lopez G, Lucero D, Faingold C, et al. Atherogenic lipoproteins in subclinical hypothyroidism and their relationship with hepatic lipase activity: response to replacement treatment with levothyroxine. Thyroid. 2016;26:365-72.

21. Plaisance EP, Grandjean PW, Mahurin AJ. Independent and combined effects of aerobic exercise and pharmacological strategies on serum triglyceride concentrations: a qualitative review. Phys Sportsmed. 2009;37:11-9.

22. Kobayashi J, Saito K, Fukamachi I, Taira K, Takahashi K, Bujo H, et al. Preheparin plasma lipoprotein lipase mass: correlation with intra-abdominal visceral fat accumulation. Horm Metab Res. 2001;33:412-6. 
23. Saiki A, Oyama T, Endo K, Ebisuno M, Ohira M, Koide N, et al. Preheparin serum lipoprotein lipase mass might be a biomarker of metabolic syndrome. Diabetes Res Clin Pract. 2007;76:93-101.

24. Miyashita Y, Ebisuno M, Ohhira M, Endoh K, Saiki A, Koide N, et al. Enhancement of serum lipoprotein lipase mass levels by intensive insulin therapy. Diabetes Res Clin Pract. 2006;72:61-7.

25. Hitsumoto T, Ohsawa H, Uchi T, Noike H, Kanai M, Yoshinuma M, et al. Preheparin serum lipoprotein lipase mass is negatively related to coronary atherosclerosis. Atherosclerosis. 2000;153:391-6.

26. Hitsumoto T, Yoshinaga K, Aoyagi K, Sakurai T, Kanai M, Uchi T, et al. Association between preheparin serum lipoprotein lipase mass and acute myocardial infarction in Japanese men. J Atheroscler Thromb. 2002;9:163-9.

27. Despres JP, Moorjani S, Lupien PJ, Tremblay A, Nadeau A, Bouchard C. Regional distribution of body fat, plasma lipoproteins, and cardiovascular disease. Arteriosclerosis. 1990;10:497-511.

28. Purnell JQ, Kahn SE, Albers JJ, Nevin DN, Brunzell JD, Schwartz RS. Effect of weight loss with reduction of intra-abdominal fat on lipid metabolism in older men. J Clin Endocrinol Metab. 2000;85:977-82.

29. Connelly PW, Hegele RA. Hepatic lipase deficiency. Crit Rev Clin Lab Sci. 1998;35:547-72.

30. Connelly PW. The role of hepatic lipase in lipoprotein metabolism. Clin Chim Acta. 1999;286:243-55.

31. Dugi KA, Brandauer K, Schmidt N, Nau B, Schneider JG, Mentz S, et al. Low hepatic lipase activity is a novel risk factor for coronary artery disease. Circulation. 2001;104:3057-62.

32. Kobayashi J, Hashimoto H, Fukamachi I, Tashiro J, Shirai K, Saito Y, et al. Lipoprotein lipase mass and activity in severe hypertriglyceridemia. Clin Chim Acta. 1993;216:113-23.

33. Tornvall P, Olivecrona G, Karpe F, Hamsten A, Olivecrona T. Lipoprotein lipase mass and activity in plasma and their increase after heparin are separate parameters with different relations to plasma lipoproteins. Arterioscler Thromb Vasc Biol. 1995;15:1086-93.

34. Miyashita K, Nakajima K, Fukamachi I, Muraba Y, Koga T, Shimomura Y, et al. A new enzyme-linked immunosorbent assay system for human serum hepatic triglyceride lipase. J Lipid Res. 2017;58:1591-7.

35. Machida T, Miyashita K, Sone T, Tanaka S, Nakajima K, Saito M, et al. Determination of serum lipoprotein lipase using a latex particle-enhanced turbidimetric immunoassay with an automated analyzer. Clin Chim Acta. 2015:442:130-5.

36. Miyashita K, Fukamachi I, Nagao M, Ishida T, Kobayashi J, Machida T, et al. An enzyme-linked immunosorbent assay for measuring GPIHBP1 levels in human plasma or serum. J Clin Lipidol. 2018;12:203-10.

37. Muraba Y, Koga T, Shimomura Y, Ito Y, Hirao Y, Kobayashi J, et al. The role of plasma lipoprotein lipase, hepatic lipase and GPIHBP1 in the metabolism of remnant lipoproteins and small dense LDL in patients with coronary artery disease. Clin Chim Acta. 2018;476:146-53.

38. Aruga M, Tokita Y, Nakajima K, Kamachi K, Tanaka A. The effect of combined diet and exercise intervention on body weight and the serum GPIHBP1 concentration in overweight/obese middle-aged women. Clin Chim Acta. 2017;475:109-15.

39. Yanagawa Y, Morimura T, Tsunekawa K, Seki K, Ogiwarao T, Kotajima N, et al. Oxidative stress associated with rapid weight reduction decreases circulating adiponectin concentrations. Endocr J. 2010;57:339-45.

40. Friedewald WT, Fredrickson DS, Levy RI. Estimation of the concentration of low-density lipoprotein cholesterol in plasma, without use of the preparative ultracentrifuge. Clin Chem. 1972;18:499-502.

41. Watanabe H, Miyashita Y, Murano T, Hiroh Y, Itoh Y, Shirai K. Preheparin serum lipoprotein lipase mass level: the effects of age, gender, and types of hyperlipidemias. Atherosclerosis. 1999;145:45-50.

42. Shirakawa T, Nakajima K, Yatsuzuka S-i, Shimomura Y, Kobayashi J, Machida $T$, et al. The role of circulating lipoprotein lipase and adiponectin on the particle size of remnant lipoproteins in patients with diabetes mellitus and metabolic syndrome. Clin Chim Acta. 2015;440:123-32.

43. Shirakawa T, Nakajima K, Shimomura Y, Kobayashi J, Stanhope K, Havel P, et al. Comparison of the effect of post-heparin and pre-heparin lipoprotein lipase and hepatic triglyceride lipase on remnant lipoprotein metabolism. Clin Chim Acta. 2015;440:193-200.

44. Greiwe JS, Holloszy JO, Semenkovich CF. Exercise induces lipoprotein lipase and GLUT-4 protein in muscle independent of adrenergic-receptor signaling. J Appl Physiol. 2000;89:176-81.
45. Pilegaard H, Keller C, Steensberg A, Helge JW, Pedersen BK, Saltin B, et al. Influence of pre-exercise muscle glycogen content on exercise-induced transcriptional regulation of metabolic genes. J Physiol. 2002;541:261-71.

46. Schrauwen-Hinderling VB, Hesselink MKC, Moonen-Kornips E, Schaart G, Kooi ME, Saris WHM, et al. Short-term training is accompanied by a down regulation of ACC2 mRNA in skeletal muscle. Int J Sports Med. 2006;27:786-91.

47. Seip RL, Mair K, Cole TG, Semenkovich CF. Induction of human skeletal muscle lipoprotein lipase gene expression by short-term exercise is transient. Am J Phys. 1997;272:E255-61.

48. Vissing $K$, Andersen $J$, Schjerling P. Are exercise-induced genes induced by exercise? FASEB J. 2004;18:94-6.

49. Mitsuzono R, Ube M. Effect of endurance training on blood lipid profiles in adolescent female distance runners. Kurume Med J. 2006;53:29-35.

50. Miyashita M, Eto M, Sasai H, Tsujimoto T, Nomata Y, Tanaka K. Twelve-week jogging training increases pre-heparin serum lipoprotein lipase concentrations in overweight/obese middle-aged men. J Atheroscler Thromb. 2010;17:21-9.

51. Kihara S, Wolle J, Ehnholm C, Chan L, Oka K. Regulation of hepatic triglyceride lipase by thyroid hormone in HepG2 cells. J Lipid Res. 1993;34:961-70.

52. Cruz-Jentoft AJ, Bahat $G$, Bauer J, Boirie $Y$, Bruyère $O$, Cederholm T, et al. Sarcopenia: revised European consensus on definition and diagnosis. Age Ageing. 2019;48:16-31.
Ready to submit your research? Choose BMC and benefit from:

- fast, convenient online submission

- thorough peer review by experienced researchers in your field

- rapid publication on acceptance

- support for research data, including large and complex data types

- gold Open Access which fosters wider collaboration and increased citations

- maximum visibility for your research: over $100 \mathrm{M}$ website views per year

At BMC, research is always in progress.

Learn more biomedcentral.com/submissions 